\title{
Effects of the Immunostimulant, Levamisole, on Opiate Withdrawal and Levels of Endogenous Opiate Alkaloids and Monoamine Neurotransmitters in Rat Brain
}

\author{
Sydney Spector, Ph.D., Inam Munjal, Ph.D., and Dennis E. Schmidt, Ph.D.
}

This report presents evidence that the immunostimulant drug levamisole, (-)-(S)-2,3,5,6-tetrahydro-6phenylimidazo[2,1-b] thiazole monohydrochloride, produced a significant elevation of endogeneous morphine and codeine levels in brain regions and peripheral organs and attenuated the effects of naltrexone-induced withdrawal in morphine-addicted rats. Levamisole also significantly altered the metabolism of norepinephrine, dopamine, and serotonin in specific brain regions. These results suggest that levamisole's attenuation of opiate withdrawal may be related to its ability to increase endogeneous opiate alkaloid levels and/or to alter central monoaminergic function. Levamisole does not have significant affinity for opiate receptors. These results raise the intriguing possibility that agents such as levamisole, which elevate the levels of the endogenous opiate alkaloids, might be useful for treating narcotic withdrawal. The mechanism for the immunostimulatory properties of agents such as levamisole and muramyl dipeptide (MDP) have not been established. We suggest that the ability of MDP and levamisole to increase endogenous opiate alkaloids may be related to their immunostimulatory properties.

[Neuropsychopharmacology 19:417-427, 1998] (c) 1998 American College of Neuropsychopharmacology. Published by Elsevier Science Inc.
KEY WORDS: Morphine; Codeine; Levamisole; Narcotic addiction; Immunostimulation

Our group (Oka et al. 1985; Donnerer et al. 1986, 1987) and others (Goldstein et al. 1985) have identified the presence of morphine and codeine in mammalian tissues and have demonstrated that mammalian tissues have the ability to synthesize the opiate alkaloids from

From the Department of Psychiatry, Vanderbilt University School of Medicine, Nashville, Tennessee, USA.

Address correspondence to: Sydney Spector, Vanderbilt University School of Medicine, Department of Psychiatry, AA-2232, Medical Center North, Nashville, TN 37232, USA.

Received October 21, 1997; revised February 4, 1998; accepted February 25, 1998. precursor compounds. Levamisole initially was studied for its anthelminthic action, but more recently has been shown to possess immunomodulatory properties (Marx 1976; Del Giaco et al. 1979). Several studies have shown that immunomodulatory drugs attenuate the severity of the naloxone precipitated withdrawal behavior of morphine-addicted rats (Dougherty et al. 1987; Dafny et al. 1983). We reported previously that the immunostimulant agent muramyl dipeptide (MDP) also modified the withdrawal behavior of morphine-addicted rats and elevated brain levels of endogenous codeine and morphine (Munjal et al. 1996). We now report that levamisole attenuated the severity of the withdrawal syndrome precipitated by naltrexone in morphine-dependent rats and, concomitantly, increased the concentrations of the 
Table 1. Effect of Levamisole (35 mg/kg IP) on Opiate Withdrawal Syndrome

\begin{tabular}{lcccc}
\hline Treatment & $\boldsymbol{n}$ & $\begin{array}{c}\text { Wet Dog } \\
\text { Shakes }\end{array}$ & $\begin{array}{c}\text { Teeth } \\
\text { Chattering }\end{array}$ & $\begin{array}{c}\text { Fecal } \\
\text { Boli }\end{array}$ \\
\hline Placebo + naltrexone & 6 & 0 & 0 & $8 \pm 2$ \\
Morphine + naltrexone & 6 & $8 \pm 1^{*}$ & $7 \pm 1^{*}$ & $\begin{array}{c}\text { Diarrhea* } \\
5 \pm 2^{* *}\end{array}$ \\
Morphine + levamisole + naltrexone & 6 & $3 \pm 1^{* *}$ & $3 \pm 1^{* *}$ & $7 \pm 2$ \\
Placebo + levamisole + naltrexone & 6 & 0 & 0 & $7 \pm 2$ \\
\hline
\end{tabular}

$n=$ number of rats/group.

Numbers represent mean \pm SEM of the times the rats exhibited the behavioral signs during the $10 \mathrm{~min}$. observation period.

${ }^{*} \mathrm{p}<.05 ;$ placebo + naltrexone vs. morphine + naltrexone.

${ }_{* *} p<.05 ;$ morphine + naltrexone vs. morphine + levamisole + naltrexone.

opiate alkaloids in various brain areas and peripheral organs. Levamisole administration also resulted in a complex regionally dependent alteration of biogenic amine metabolism in brain.

\section{METHOD AND MATERIALS}

\section{Behavioral Assessment of Opiate Withdrawal}

Male Sprague-Dawley rats (200-250 g) were used in these studies. Under light halothane anesthesia, mor- phine pellets (containing $75 \mathrm{mg}$ morphine base National Institute of Drug Abuse [NIDA], Rockville, MD USA) were implanted subcutaneously daily for 3 days. Control rats received placebo pellets implanted using identical procedures. On the 4th day, 24 hours after the last pellet implantation, the two most recent pellets were removed from the rat under light halothane anaesthesia. Two hours and 15 min later, the rats received levamisole $(35 \mathrm{mg} / \mathrm{kg} \mathrm{IP})$ and $20 \mathrm{~min}$ later were given naltrexone $(1 \mathrm{mg} / \mathrm{kg} \mathrm{IP})$. The number of wet dog shakes, episodes of teeth chattering, and fecal boli were

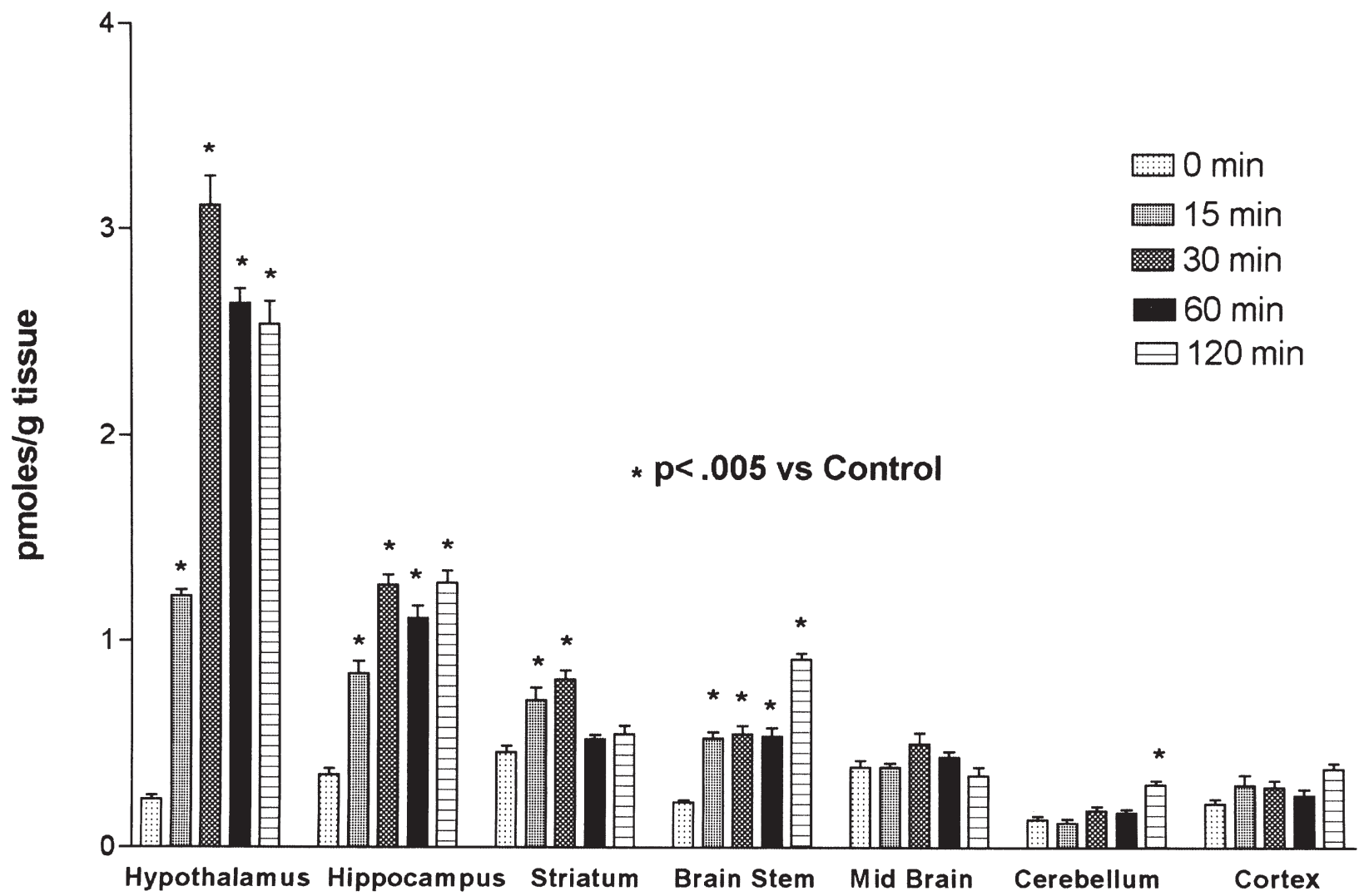

Figure 1. Time-dependent effects of levamisole $(35 \mathrm{mg} / \mathrm{kg}$, IP) on morphine content in brain regions at various times. Values represent the mean pmoles/mg tissue + SEM of six rats per time point. Significance of the individual time points were determine by Bonferroni's post hoc testing. 
counted for $10 \mathrm{~min}$ following the administration of naltrexone by observing the rats in a clear Plexiglass cage to which the animals had been previously adapted prior to drug administration. These behavioral withdrawal indicators were chosen, because they represent readily identified and distinctive withdrawal characteristics that can be accurately quantified with a minimum of subjective interpretation.

\section{Extraction of Morphine and Codeine}

The method described by Donnerer et al. (1987) was used for the extraction and quantitation of codeine and morphine from tissues. Groups of six morphine-naive rats were pretreated with either saline or levamisole (35 $\mathrm{mg} / \mathrm{kg}$, IP). At the indicated times, the groups were rapidly rendered unconscious with $50 \% \mathrm{CO}_{2}$ and sacrificed by decapitation. Brains and peripheral organs were removed and washed free of blood with ice-cold normal saline. The peripheral organs were frozen, and the brains were further dissected on wet ice and the resulting brain regions immediately frozen on dry ice. For analysis, the brain regions or whole peripheral organs were rapidly homogenized without prior thawing in ice-cold $10 \mathrm{mM} \mathrm{HCl}$ (polytron homogenized, setting 9 for $30 \mathrm{~s}$, to yield $100 \mathrm{mg}$ tissue/ml). A $100 \mu \mathrm{l}$ portion of the brain homogenate was removed for analysis of monoamine metabolites. Concentrated $\mathrm{HCl}$ was added in a ratio of $6 \mathrm{ml}$ of acid to $10 \mathrm{ml}$ of remaining tissue homogenate, the samples were vortexed, and the glucuronide and sulphate conjugates of morphine and codeine were hydrolyzed by heating in a water bath for 30 min at 95 to $100^{\circ} \mathrm{C}$. The samples were centrifuged for 30 $\min$ at $10,000 \times g$ at $4^{\circ} \mathrm{C}$ and filtered through a small plug of glass wool contained in a small glass funnel to remove particulate material. The $\mathrm{pH}$ of the samples were adjusted to 8.5 to 9.0 , and the hydrolyzed free alkaloids were extracted using 5 volumes of 1:9 mixture of n-butanol in chloroform. The organic phase was collected, the compounds of interest were back extracted into 2 to $2.5 \mathrm{ml}$ of $10 \mathrm{mM} \mathrm{HCl}$, and the resulting aqueous acid phase was evaporated to dryness in a Savant evaporation centrifuge.

The dried sample was reconstituted in $2 \mathrm{ml}$ of phosphate-buffered saline ( $\mathrm{pH} 7.4)$, and the $\mathrm{pH}$ was adjusted to 8.5 to 9.0 with $1 \mathrm{~N} \mathrm{NaOH}$. The sample was then passed through C-18 Sep Pak cartridge, which had been

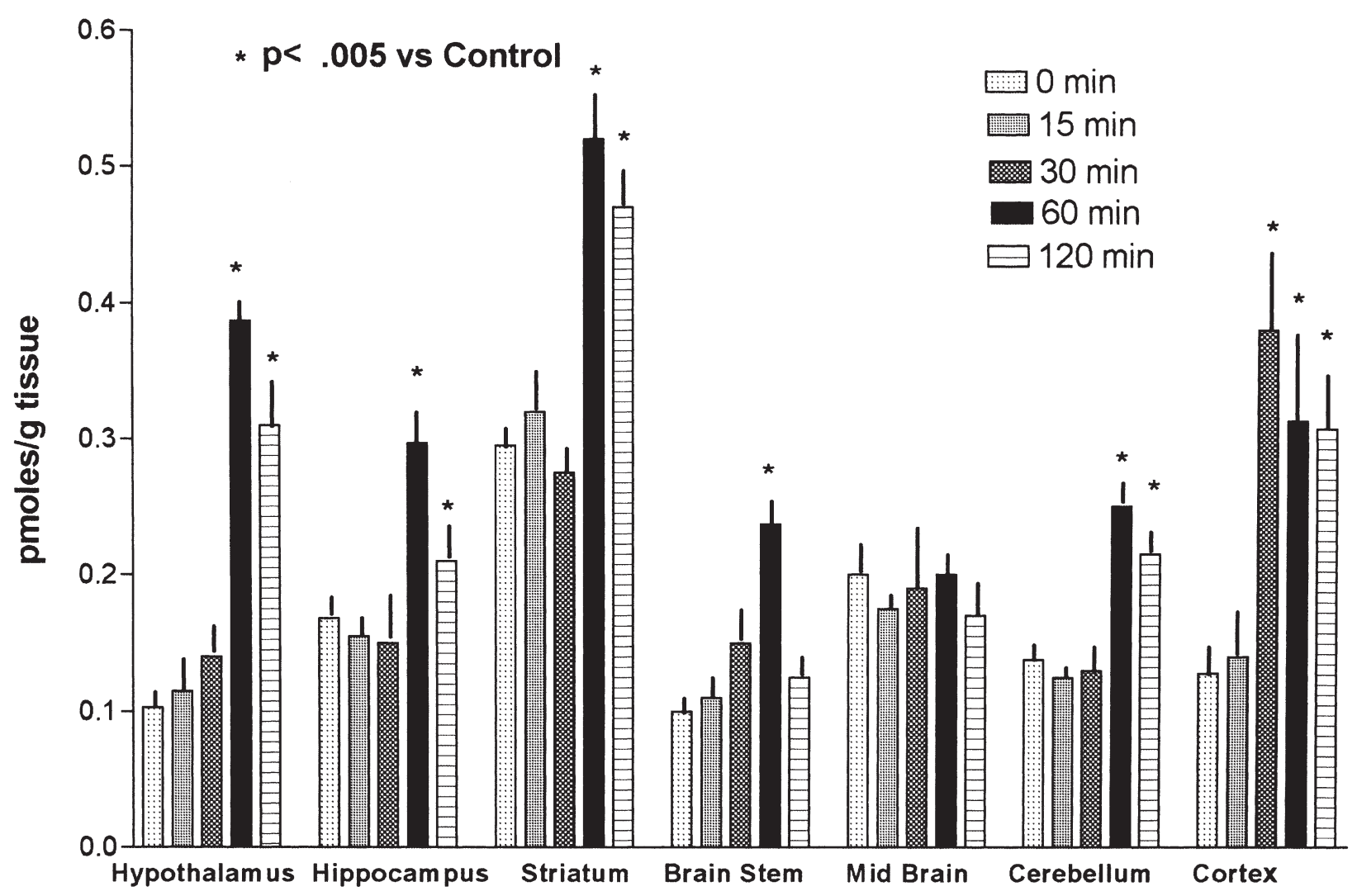

Figure 2. Time-dependent effects of levamisole $(35 \mathrm{mg} / \mathrm{kg}, \mathrm{IP})$ on codeine content in brain regions at various times. Values represent the mean pmoles/mg tissue + SEM of six rats per time point. Significance of the individual time points were determine by Bonferroni's post hoc testing. 
pretreated with $5 \mathrm{ml}$ methanol wash. Following application of the samples, the column was washed twice with $10 \mathrm{ml}$ of distilled water, and the eluate was discarded. The alkaloids were then eluted with $7 \mathrm{ml}$ of a mixture of $\mathrm{H}_{2} \mathrm{O}(95.5 \%)$, 1-propanol $(3 \%)$, pyridine $(0.8 \%)$, and glacial acetic acid (0.3\%). The eluate was evaporated to dryness in a Savant evaporation centrifuge.

\section{HPLC Separation of Morphine and Codeine}

The samples were resuspended in $250 \mu \mathrm{l}$ of the highperformance liquid chromatography (HPLC) mobile phase (water, $98.4 \%$; 1 -propranol, $0.5 \%$; pyridine, $0.8 \%$; glacial acetic acid, $0.3 \%$; $\mathrm{pH}$ 5.2). The samples were filtered through 6.2- $\mu \mathrm{m}$ Z-bind filter (2-spin, Gelman Sciences) and injected onto a $25 \mathrm{~cm} \times 4 \mathrm{~mm}$ Lichrosorb RP-18 $10 \mu \mathrm{m}$ column (Alltech) at a flow rate $1.5 \mathrm{ml} /$ $\mathrm{min}$, and $1 \mathrm{~min}$ fractions were collected using Foxy fraction collector (ISCO). The retention times were approximately $8 \mathrm{~min}$ for morphine and $19 \mathrm{~min}$ for codeine. The eluated fractions were then evaporated to dryness.

\section{Radioimmunoassay for Morphine and Codeine}

The dried samples were resuspended in $100 \mu$ l of phosphate buffered saline ( $\mathrm{pH} 7.4$ ), $50 \mu \mathrm{l}$ of the morphine antibody, $1^{125}$ morphine (Abuserum Kit, Roche Pharmaceuticals) were added, and the samples were incubated for $90 \mathrm{~min}$ at $4^{\circ} \mathrm{C}$. Following equilibration, $250 \mu \mathrm{l}$ of saturated ammonium sulfate was added, and after $45 \mathrm{~min}$, samples were filtered through GF/B glass filters. Filters were counted in a gamma counter, and concentrations of the alkaloids were estimated using the Riacalc program (LKB Wallace).

\section{Analysis of Monoamine Neurotransmitter Metabolites}

The monoamine neurotransmitters and their metabolites were determined in the dissected brain regions using the method of Schmidt et al. (1990). The HCl homogenate from above was centrifuged at $10,000 \times g$ for 10 $\mathrm{min}$, and the clear supernatant was decanted into a clean tube and stored at $-70^{\circ} \mathrm{C}$ until analysis. For anal-

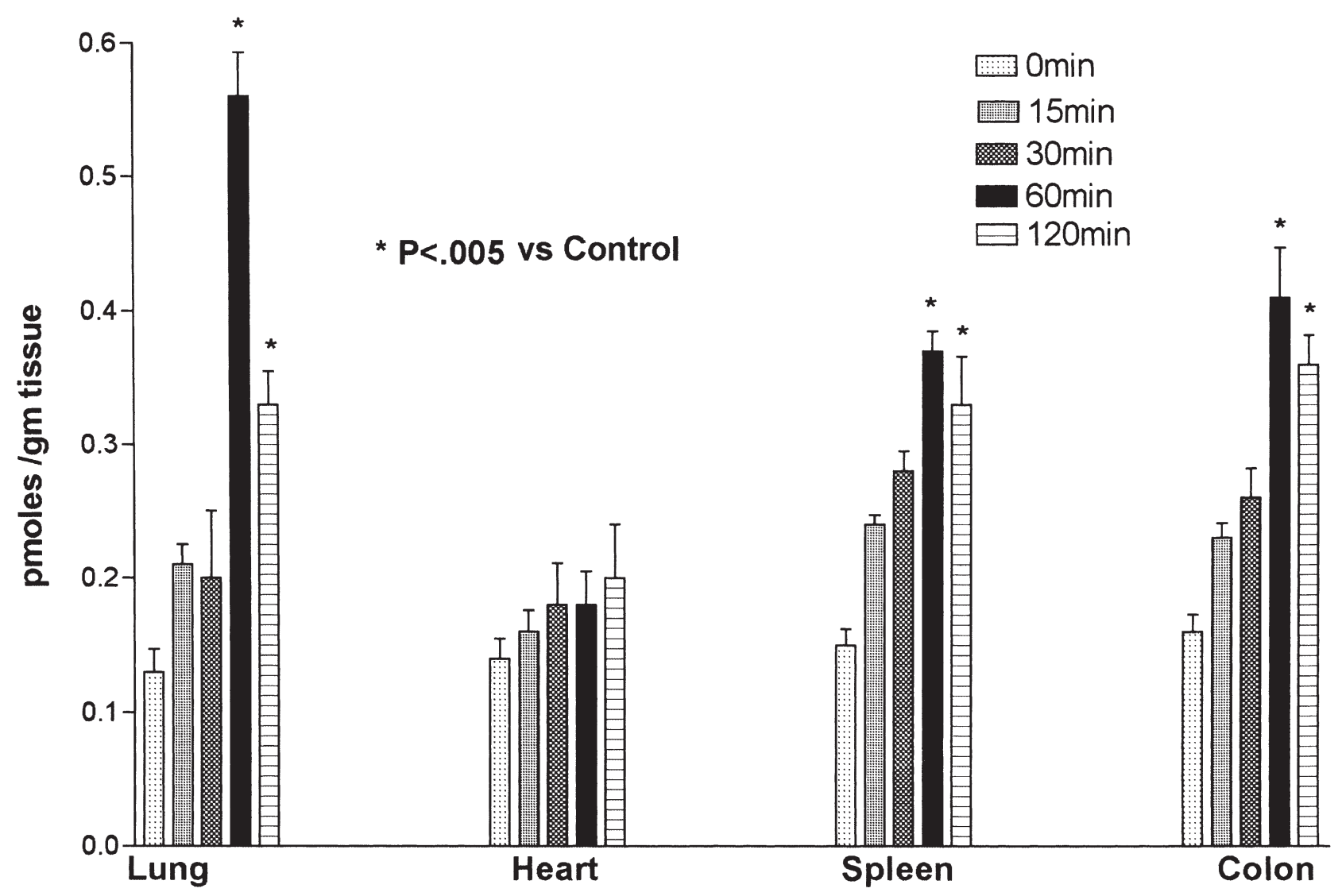

Figure 3. Time-dependent effects of levamisole $(35 \mathrm{mg} / \mathrm{kg}, \mathrm{IP})$ on morphine content in peripheral tissues at various. Values represent the mean pmoles/mg tissue + SEM of six rats per time point. Significance of the individual time points were determine by Bonferroni's post hoc testing. 


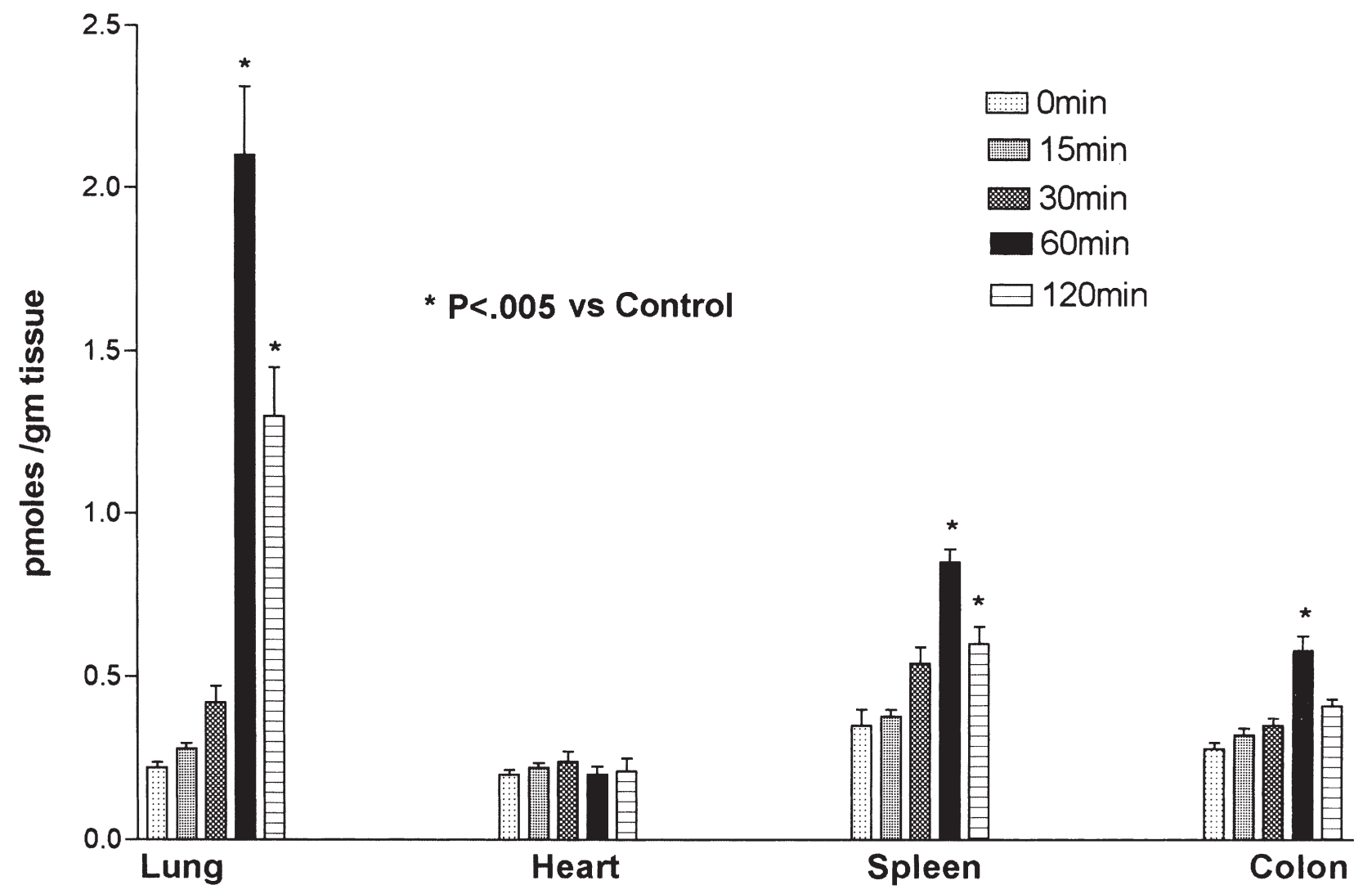

Figure 4. Time-dependent effects of levamisole $(35 \mathrm{mg} / \mathrm{kg}, \mathrm{IP})$ on codeine content in peripheral tissues at various. Values represent the mean pmoles $/ \mathrm{mg}$ tissue + SEM of six rats per time point. Significance of the individual time points were determine by Bonferroni's post hoc testing.

ysis 50 to $100 \mu$ l of the supernatant was diluted with an equal volume of mobile phase containing $1 \mathrm{pmol} / \mu \mathrm{l}$ of the internal standard 3,4-dihydroxybenzylamine and injected onto the HPLC system.

\section{Statistical Analysis}

Time-dependent changes in the levels of morphine, codeine, and the monoamine neurotransmitters and metabolites were determined by analysis of variance (ANOVA) followed by Bonferroni's post-hoc testing of individual values using Sigma Stat (Jandel). Changes in indices of withdrawal were determined by $t$-test.

\section{RESULTS}

Because the central effects of levamisole on the narcotic alkaloids and monoamine neurotransmitters were evident within 15 min (see below), opiate-addicted rats were pretreated with levamisole $20 \mathrm{~min}$ before the narcotic antagonist naltrexone was administered. Table 1 shows that levamisole significantly attenuated the behavioral indicators of narcotic withdrawal that were as- sessed. Other prominent withdrawal characteristics, such as vocalization and irritability, especially during handling, penile erection, ptosis, and salivation also seemed to be attenuated by levamisole pretreatment. However, these data were not recorded, because these behaviors are more difficult to quantitate and involve substantial subjective judgment. Levamisole alone elicited no obvious behavioral effects when administered to nonaddicted rats.

The levels of the opiate alkaloids were measured in specific brain regions at multiple time points following IP injection of levamisole $(35 \mathrm{mg} / \mathrm{kg}$ ). The levamisoleinduced alterations in monoamine metabolism and increase in the endogenous opiate alkaloids were measured in morphine-naive rats. It is assumed that the same changes are induced in the morphine pretreated rats. As shown in Figure 1, levamisole significantly increased morphine $(p<.005)$ in the hypothalamus, hippocampus, brain stem, and cerebellum, although the time course and extent of morphine increase differed between brain regions. Morphine levels in the hippocampus, hypothalamus, brainstem, and striatum were significantly increased within $15 \mathrm{~min}(p<.005)$. The maximal increase $(p<.005)$ was observed at $30 \mathrm{~min}$ in 
Table 2. Time Course of Regional Effect of Lavamisol on Noradrenergic Parameters

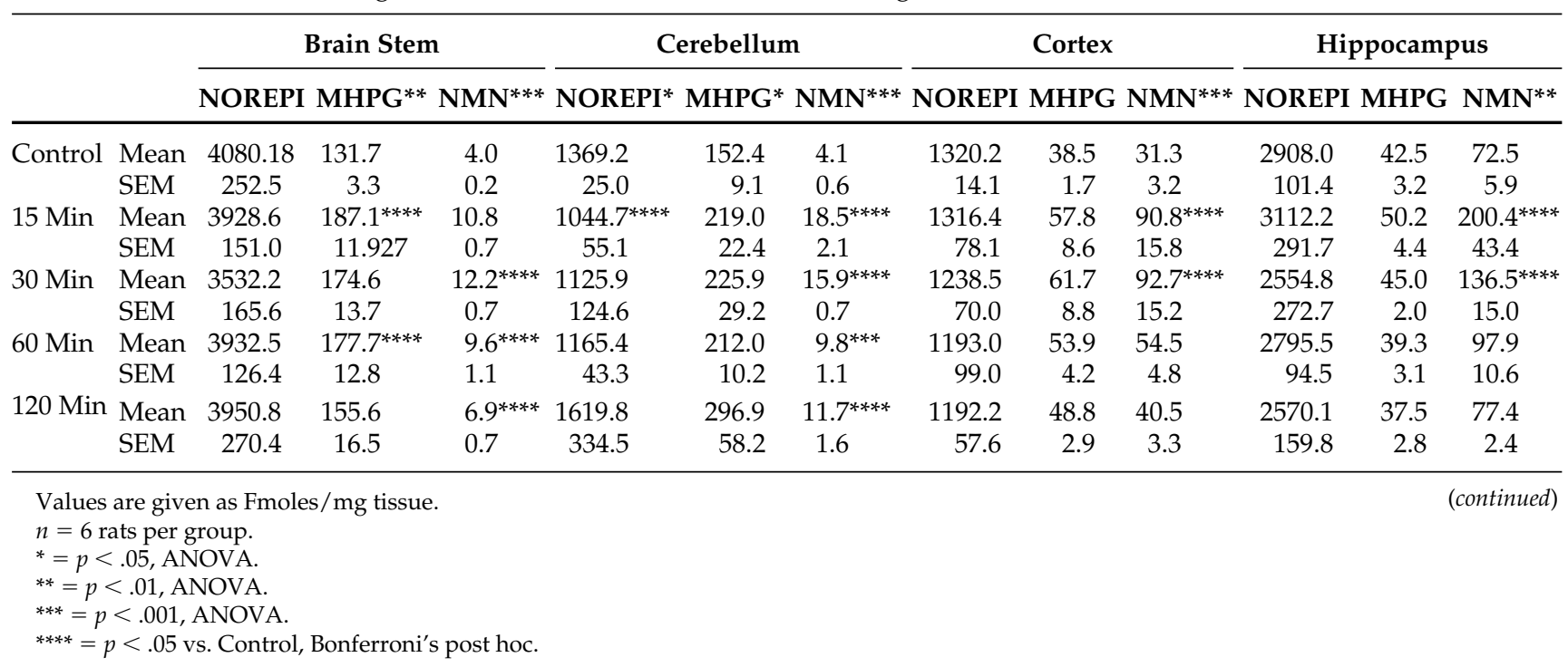

the hippocampus, hypothalamus, and striatum; whereas, levels in the cerebellum $(p<.005)$ were maximal at the 120 -min time point. The maximal increases ranged from 15 -fold in hypothalamus to about 2-fold in the striatum. The modest increase in morphine levels seen in cortex and midbrain was not significant during the 2-h study period.

The levamisole-induced, time-dependent increase in codeine levels in brain showed a different pattern (Figure 2). Codeine levels were significantly increased $(p<$ .005 ) in all regions, except midbrain. In contrast to morphine, these increases at specific times were most evident at the latter time points; that is, 60 and $120 \mathrm{~min}$.

Morphine and codeine levels were also measured in lung, heart, spleen, and colon following levamisole administration (Figure 3). Morphine levels were significantly elevated in lung, spleen, and colon $(p<.005)$, and these changes were significant at 60 and $120 \mathrm{~min}$ following levamisole administration. Morphine levels in the heart showed no significant changes. The codeine content of lung, spleen, and colon increased in a timedependent fashion (Figure 4). The increases were significant $(p<.005)$ in the lung and spleen at both 60 and $120 \mathrm{~min}$ and at $120 \mathrm{~min}$ in the colon. As with morphine, codeine levels in the heart were unaffected.

Levamisole administration resulted in a complex regional and temporal pattern of changes in norepinephrine (Table 2), dopamine (Table 3), and serotonin (Table 4) metabolism in brain. As shown in Table 2, although levamisole administration did not alter norepinephrine levels in most brain regions, there was a slight transient decrease in cerebellum and midbrain. However, the most consistent effect observed was a large $(p<.001)$ and rapid time-dependent increase in the levels of normetanephrine (NMN), a minor norepinephrine me- tabolite, in all brain regions. The elevation of NMN levels was accompanied by a more modest, although significant, time-dependent increase in the levels of free MHPG, the major CNS norepinephrine metabolite, in the brain stem $(p<.01)$, cerebellum $(p<.05)$, hypothalamus $(p<.05)$, and midbrain $(p<.01)$.

The time-dependent effects of levamisole on dopaminergic parameters were especially complex and were strikingly regionally dependent (Table 3 ). The effects of levamisole on dopamine levels tended to be correlated to its effects on DOPAC and HVA in some brain regions. Dopamine levels were increased in the brain stem $(p<.05)$, cerebellum $(p<.01)$, hippocampus $(p<$ $.05)$, hypothalamus $(p<.05)$, and midbrain $(p<.01)$ regions that also had increased HVA and/or DOPAC levels. However, in the cortex and striatum, regions where HVA and DOPAC levels significantly decreased, the dopamine content was unchanged. Levamisole caused a significant increase in the predominant dopamine metabolite, HVA, in brain stem $(p<.01)$, cerebellum $(p<$ $.01)$, and hypothalamus $(p<.01)$. An increase in HVA levels also seemed evident in the hippocampus and midbrain, but did not achieve statistical significance. Conversely, the levels of HVA in the striatum $(p<.001)$ and cortex $(p<.01)$ were significantly decreased. The increases in HVA that occurred were rapid and persisted for at least the 120-min duration of the study in most regions; whereas, the decreases observed in the cortex and striatum were more delayed and were most evident at the 120-min time point. The effect of levamisole on the minor dopamine metabolite DOPAC paralleled that of HVA. That is, DOPAC levels significantly increased in brain stem $(p<.001)$, hippocampus $(p<$ $.05)$, hypothalamus $(p<.001)$, and were significantly decreased in cortex $(p<.001)$ and striatum $(p<.001)$. In 
Table 2. (continued)

\begin{tabular}{|c|c|c|c|c|c|c|c|c|c|c|}
\hline & & \multicolumn{3}{|c|}{ Hypothalamus } & \multicolumn{3}{|c|}{ Midbrain } & \multicolumn{3}{|c|}{ Striatum } \\
\hline & & NOREPI & MHPG*** & $\mathbf{N M N}^{* * *}$ & NOREPI $^{* *}$ & MHPG** & $\mathbf{N M N}^{* * *}$ & NOREPI & MHPG & $\mathbf{N M N}^{* * *}$ \\
\hline \multirow[t]{2}{*}{ Control } & Mean & 10134.6 & 34.6 & 64.4 & 3570.5 & 29.8 & 39.7 & 833.2 & 32.7 & 2.6 \\
\hline & SEM & 513.8 & 2.5 & 4.9 & 120.1 & 0.8 & 6.4 & 130.5 & 5.8 & 1.6 \\
\hline \multirow[t]{2}{*}{15 Min } & Mean & 10421.5 & $53.4^{* * * *}$ & $290.6^{* * * *}$ & $3328.3^{* * * *}$ & $43.3^{* * * *}$ & $150.6^{* * * *}$ & 794.9 & 34.2 & $25.1^{* * * *}$ \\
\hline & SEM & 417.0 & 4.7 & 11.1 & 326.3 & 2.8 & 11.8 & 112.1 & 1.2 & 6.1 \\
\hline \multirow[t]{2}{*}{30 Min } & Mean & 9950.0 & $61.6^{* * * *}$ & $229.7^{* * * *}$ & 2652.9 & 38.6 & $136.7^{* * * *}$ & 680.2 & 42.2 & $37.9^{* * * *}$ \\
\hline & SEM & 1280.1 & 2.3 & 11.1 & 77.5 & 3.8 & 15.8 & 99.3 & 4.3 & 1.9 \\
\hline \multirow[t]{2}{*}{$60 \mathrm{Min}$} & Mean & 9659.9 & 43.4 & $128.8^{* * * *}$ & 3230.8 & 32.9 & $103.0^{* * * *}$ & 1235.3 & 40.4 & $35.9^{* * * *}$ \\
\hline & SEM & 692.2 & 3.6 & 13.7 & 168.5 & 0.7 & 3.9 & 133.8 & 3.3 & 8.4 \\
\hline \multirow[t]{2}{*}{120 Min } & Mean & 9799.9 & 39.1 & $97.5^{* * * *}$ & 3269.3 & 26.9 & 66.5 & 975.2 & 31.0 & $22.6^{* * * *}$ \\
\hline & SEM & 478.6 & 5.1 & 1.9 & 135.2 & 3.6 & 4.0 & 178.8 & 4.0 & 6.3 \\
\hline
\end{tabular}

contrast to the widespread effect of levamisole on formation of the 3-O-methyl norepinephrine metabolite $\mathrm{NMN}$, the 3-O-methylated metabolite of dopamine, 3-methoxytyramine (3-MT), rapidly increased only in the hypothalamus $(p<.001)$. In the other two regions where 3-MT was detected, there was a tendency for the levels to decrease rather than to increase.

A time-dependent effect of levamisole on serotonin metabolism was also observed (Table 4). There was a delayed increase in serotonin levels in the brain stem $(p<.05)$, hippocampus $(p<.01)$, hypothalamus $(p<$ $.01)$, and midbrain $(p<.01)$, which was evident only at the 60- and/or 120-min time points. This increase in 5-HT levels was accompanied by a similarly delayed increase in 5-HIAA levels only in the brain stem and midbrain. In marked contrast, there was a rapid, but brief, decrease in 5-HIAA levels in the midbrain at the 15-min time period $(p<.05)$. There was a tendency for this early decrease in 5-HIAA levels to occur in the cerebellum, cortex, and striatum, although the decease did not achieve statistical significance in these regions.

\section{DISCUSSION}

Levamisole was originally developed as a treatment for bacterial, helminthic, and viral diseases (Janssen 1976; Symens and Rosenthal 1977; Renoux 1980; Moertel et al. 1990), but it is increasingly used as an immunostimulant. The results presented here demonstrate that systemic administration of levamisole reduced the symptoms of naltrexone-induced morphine withdrawal, produced a significant increase in the levels of endogenous morphine and codeine in brain and peripheral organs, and significantly altered the metabolism of the monoamine neurotransmitters in specific brain regions. Although only a limited number of the withdrawal characteristics attenuated by levamisole were recorded in a comparatively small group of animals, the antiwithdrawal effects were clearly evident and suggest that levamisole's actions are centrally mediated and are not limited to these peripheral withdrawal manifestations.

Because levamisole has no appreciable affinity for the mu receptor $(\mathrm{Ki}>10 \mu \mathrm{m}$, unpublished observations) it is unlikely that levamisole's effects are mediated by direct actions at the mu receptor site. Morphine has a high affinity for the mu receptor in brain $\left(\mathrm{K}_{\mathrm{d}}=\right.$ $0.5-1.5 \mathrm{~nm}$ ). It also seems likely that the endogenous form of morphine is a sulphate conjugate (Donnerer et al. 1987). Brown et al. (1985) have reported that the efficacy of the 6-sulphate conjugate of morphine for inducing $\mathrm{mu}$ receptor-mediated pharmacological effects is 3 to 30 times greater than morphine itself. Furthermore, it has been demonstrated that morphine in the brain behaves as a neurotransmitter; that is, it is located in specific neurons and can be released under conditions known to release other neurotransmitters (Bianchi et al. 1994). Because the antibody does not recognize morphine conjugates, the method employed includes a preanalysis hydrolysis step and, thus, measured the total amount of morphine present. As a consequence, it does not differentiate between presynaptic storage pools of the active morphinergic ligand and probable postrelease inactive metabolites, most likely conjugates in the 3-position. Therefore, the levamisole-induced increase in the total amount of morphine present almost certainly represents a rapid increase in the de novo synthesis of morphine from a currently unidentified precursor pool with low affinity for morphine antibody and is not detected by the radioimmunoassay employed. As observed in other neurotransmitter systems, it is likely that this increase in synthesis occurs as a consequence of the increased demand resulting from increased presynaptic release. Moreover, the concentration of morphine released into these "morphinergic" synapses in brain will be significantly more concentrated than the average tissue concentrations we have measured. The narcotic antagonist naltrexone also has high affinity for the mu receptor $\left(\mathrm{K}_{\mathrm{d}}=1.5 \mathrm{~nm}\right)$, and it is assumed that displacement of morphine from the mu receptor is the 


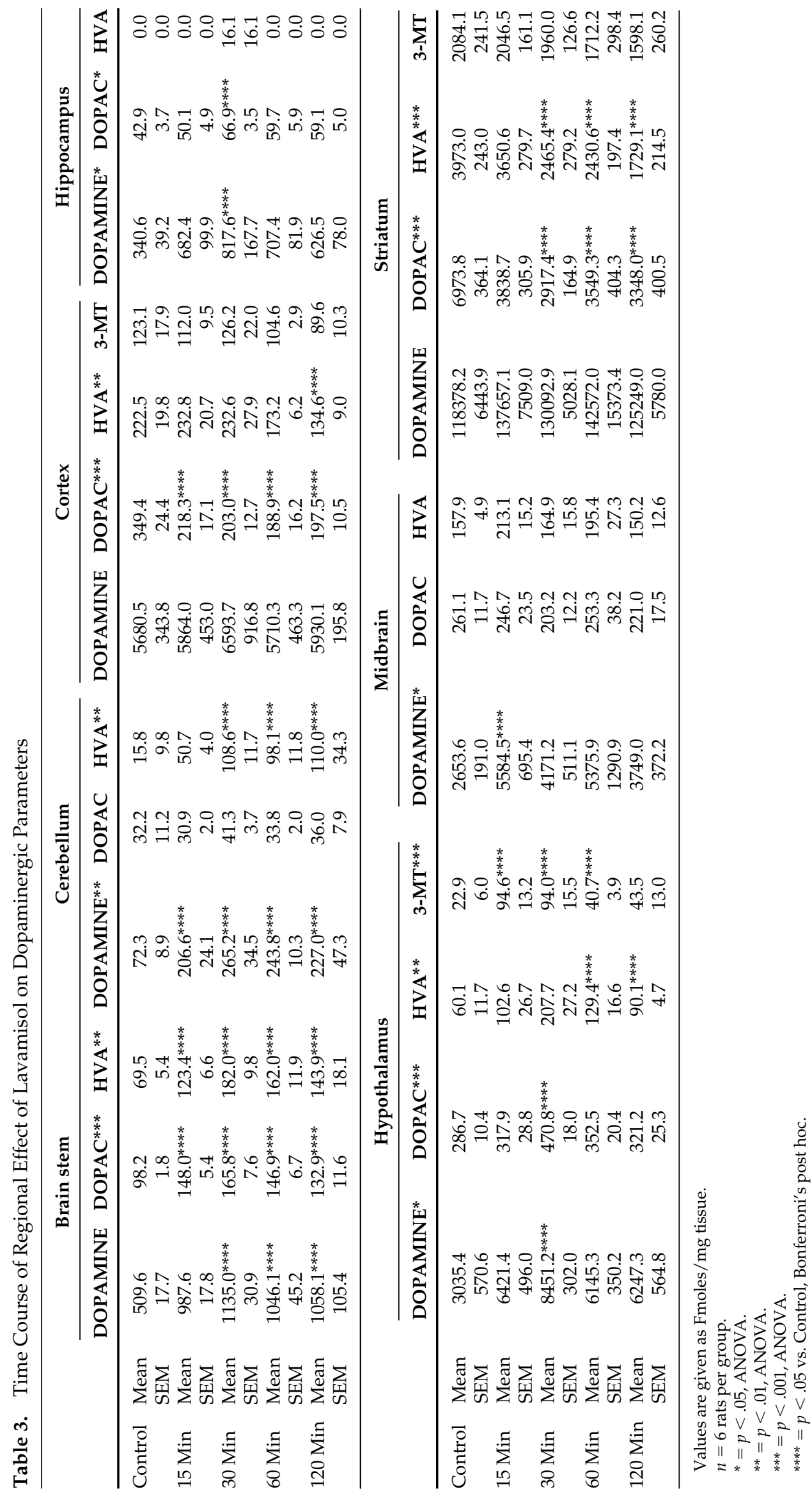


Table 4. Time Course of Regional Effect of Lavamisol on Serotonergic Parameters

\begin{tabular}{|c|c|c|c|c|c|c|c|c|c|}
\hline & & \multicolumn{2}{|c|}{ Brain Stem } & \multicolumn{2}{|c|}{ Cerebellum } & \multicolumn{2}{|c|}{ Cortex } & \multicolumn{2}{|c|}{ Hippocampus } \\
\hline & & $5-\mathrm{HT}^{*}$ & 5-HIAA ${ }^{* * *}$ & 5-HT & 5-HIAA & 5-HT & 5-HIAA & $5-\mathrm{HT}^{* *}$ & 5-HIAA \\
\hline \multirow[t]{2}{*}{ Control } & Mean & 3735.9 & 1231.4 & 303.8 & 244.6 & 1520.7 & 504.2 & 1668.8 & 1262.4 \\
\hline & SEM & 108.9 & 63.4 & 21.6 & 15.4 & 57.4 & 38.2 & 98.2 & 63.5 \\
\hline \multirow[t]{2}{*}{$15 \mathrm{Min}$} & Mean & 3759.1 & 1140.3 & 287.1 & 191.7 & 1447.5 & 402.1 & 1959.6 & 1205.4 \\
\hline & SEM & 186.2 & 51.5 & 9.8 & 19.5 & 78.8 & 27.6 & 133.1 & 30.4 \\
\hline \multirow[t]{2}{*}{$30 \mathrm{Min}$} & Mean & 3773.3 & 1382.0 & 296.2 & 227.1 & 1405.5 & 522.2 & 2093.5 & 1230.1 \\
\hline & SEM & 261.6 & 36.5 & 43.4 & 20.8 & 92.1 & 30.7 & 154.4 & 96.8 \\
\hline \multirow[t]{2}{*}{60 Min } & Mean & $4790.0^{* * * *}$ & 1449.5 & 297.2 & 253.1 & 1364.1 & 520.3 & $2335.7^{* * * *}$ & 1363.1 \\
\hline & SEM & 372.7 & 53.3 & 26.6 & 17.9 & 101.9 & 40.8 & 77.7 & 28.7 \\
\hline \multirow[t]{4}{*}{$120 \mathrm{Min}$} & Mean & $4753.2^{* * * *}$ & $1863.0^{* * * *}$ & 319.1 & 361.5 & 1865.4 & 556.0 & 2045.3 & 1397.8 \\
\hline & SEM & 204.1 & 74.6 & 24.9 & 126.4 & 219.6 & 16.9 & 66.8 & 33.7 \\
\hline & & & \multicolumn{2}{|c|}{ Hypothalamus } & \multicolumn{2}{|c|}{ Midbrain } & & \multicolumn{2}{|c|}{ Striatum } \\
\hline & & $5-\mathrm{H}$ & $\mathrm{T}^{* *}$ & 5-HIAA & $5-\mathrm{HT}^{* *}$ & 5-HIAA* & & 5-HT & 5-HIAA \\
\hline \multirow[t]{2}{*}{ Control } & Mean & 3466 & & 2456.9 & 3784.3 & 2117.0 & & 912.1 & 4221.5 \\
\hline & SEM & 210 & & 74.5 & 242.4 & 120.7 & & 63.6 & 212.7 \\
\hline \multirow[t]{2}{*}{15 Min } & Mean & 4122 & & 2149.2 & 3959.4 & 1752.1 & & 1090.3 & 3490.5 \\
\hline & SEM & 219 & & 163.9 & 160.4 & 51.4 & & 166.6 & 289.7 \\
\hline \multirow[t]{2}{*}{30 Min } & Mean & 4702 & $3^{* * * *}$ & 2151.0 & 3963.5 & 2133.3 & & 1240.3 & 3043.1 \\
\hline & SEM & 397 & & 98.8 & 153.0 & 75.8 & & 55.3 & 401.0 \\
\hline \multirow[t]{2}{*}{$60 \mathrm{Min}$} & Mean & 4633 & $4^{* * * *}$ & 2168.7 & 4625.7 & 2456.4 & & 1158.5 & 3622.2 \\
\hline & SEM & 187 & & 76.4 & 104.5 & 58.0 & & 72.2 & 465.8 \\
\hline \multirow[t]{2}{*}{$120 \mathrm{Min}$} & Mean & 4611 & $2^{* * * *}$ & 2491.6 & $5468.2^{* * * *}$ & 2687.9 & & 1018.5 & 3513.0 \\
\hline & SEM & 127 & & 62.9 & 532.3 & 77.4 & & 115.4 & 276.4 \\
\hline
\end{tabular}

pharmacological basis for its ability to precipitate the symptoms of narcotic withdrawal. Because of their similar affinities for the mu receptor, significant displacement of morphine will, therefore, occur when the concentrations of morphine and naltrexone are approximately equal. The endogenous levels of morphine in whole brain tissue produced by levamisole, when expressed as pmoles/g wet weight tissue, are also in the $\mathrm{nM}$ range. Thus, it is logical to assume that the ability of levamisole to ameliorate the acute effects of naloxoneinduced withdrawal may be related to the displacement of naltrexone from the mu receptor by increased levels of an endogenous opiate alkaloid. However, a number of other agents act at nonopioid receptors, such as the serotonergic, noradrenergic, and glutaminergic receptors, which have significant effects on narcotic addiction and withdrawal (Herman and O'Brien 1997). It is possible that the effects of levamisole reported here may also be mediated through a currently unidentified nonopioid receptor(s).

Levamisole was also shown to alter significantly the metabolism of norepinephrine, dopamine, and serotonin in brain in a regionally specific manner. The func- tional implications of these complex changes are difficult to interpret; moreover it is not possible to determine from this study whether these changes result from direct effects of levamisole on monoamine metabolism or whether they result from the effects of increased endogenous morphine levels on monamine metabolism.

There is an extensive literature indicating that pharmacological doses of morphine have significant effects on these neurotransmitter systems, suggesting that at least some of the monoaminergic metabolism may be changes secondary to increased morphine levels. Of specific interest is the dopaminergic system. One of the properties of the opiates thought to be related to their abuse potential is that they act as powerful reinforcers of the reward system. There is increasing evidence that the dopaminergic system is implicated in the reinforcing actions of drugs of abuse (Wise 1989; BettnerJohnson and Nestler 1991), and it has been reported that these reinforcing properties can be reduced by dopamine receptor antagonists (Pfeifer and Samson 1988). Levamisole caused an increase in HVA and DOPAC levels in reward-associated brain regions, which likely 
indicates increased neuronal release of dopamine. It is, therefore, possible that, in addition to reducing the physical symptoms of narcotic withdrawal, levamisole might also attenuate the effects of the narcotic-induced withdrawal on the reward system and/or alter the reward properties of narcotic agonists.

Methadone is widely used in the treatment of narcotic addiction, but its efficacy derives from its cross tolerance with heroin and morphine (Dole and Nyswander 1965). Thus, although methadone administration does prevent withdrawal effects and reduces drugseeking behavior, it does not alleviate the neurobiological basis of the addiction. No evidence has been presented that levamisole's use as an immunostimulant has resulted in any addictive-type problems, and this suggests that its abuse potential is low. The results presented here, although they do not conclusively identify its mechanism of actions, raise the possibility that drugs such as levamisole may constitute a new class of nonaddictive agents with which to treat aspects of narcotic addiction.

Peripherally, levamisole elevated morphine content in lung, spleen, and colon, and these changes may also be involved in the antiwithdrawal effects. For example, one of the prominent signs that occur during opiate withdrawal is a profound diarrhea. The elevated morphine levels seen in the colon could attenuate the diarrhea by modifying fluid absorption from the lumen and/or by reducing peristalsis.

The presence of codeine in both CNS and peripheral tissues and the independent pattern and time course of its elevation by levamisole suggests that codeine may not act solely as the precursor in the synthesis of morphine, but that it may have an independent role. For example, in the cortex, morphine is unchanged following levamisole administration; whereas, the levels of codeine are elevated. Codeine levels also remain elevated for longer times than morphine levels in most organs.

The mechanism(s) responsible for the immunostimulatory actions of levamisole are not understood. There is increasing evidence that communication exists between the immune and central nervous systems, which seems to involve jointly biogenic amines (Ernstrom and Soder 1975), hormones (Bessedovsky et al. 1986), and neuropeptides (Payan and Goetzel 1985; O'Dorisio et al. 1985; Felton et al. 1985). We have previously demonstrated that a chemically unrelated immunostimulant agent, muramyl dipeptide, also produced a significant increase in the endogenous levels of the opiate alkaloids morphine and codeine (Munjal et al. 1996). Thus, it is not unreasonable to speculate that the shared ability of these agents to increase morphine and/or codeine levels may be functionally related to their immunostimulatory properties. The widespread effects of levamisole on both the opiate system and on monoaminergic function in brain suggest that its use as an immunostimulant agent might include studies to determine whether this use might not produce significant, previously unanticipated behavioral effects in these subjects.

In summary, we have demonstrated that levamisole is able to attenuate the physical symptoms of naloxoneinduced morphine withdrawal. We postulate that this effect is related to the ability of levamisole to increase endogenous morphine and codeine levels and most likely also involves changes in monoaminergic function in brain. These results suggest that levamisole may represent a new class of agents with the potential for treatment of narcotic addiction.

\section{REFERENCES}

Bessedovsky H, Del Rey A, Sorkin E, Dimarello CA (1986): Immunoregulatory feedback between interleukin-1 and glucocorticoid hormones. Science 233:652-654

Bettner-Johnson D, Nestler EJ (1991): Morphine and codeine exert common chronic action in tyrosine hydroxylase in dopaminergic reward regions. J Neurochem 51:344-347

Bianchi E, Guarna M, Tagliamonte A (1994): Immunocytochemical localization of endogenous codeine and morphine. Adv Neuroimmunol 4:83-92

Brown CE, Roerig SC, Burger VT, Cody RB, Fujimoto JM (1985): Analgesic potencies of morphine - 3 and 6 sulfates after intracerebroventricular administration in mice. Relationship to structural characteristics defined by mass spectrometry and nuclear magnetic resonance. J Pharmaceut Sci 74:821-824

Dafny N, Zielinski M, Reyes-Vazquez C (1983): Alteration of morphine withdrawal to naloxone by interferon. Neuropeptides 3:453-463

Del Giaco GS, Tognella S, Leone AL (1979): Interference of levamisole with inhibition of E. Rosette formation by Hodgkins disease and systemic lupus erythematosis cytotoxic serum. Blood 53:1002-1007

Dole VP, Nyswander ME (1965): A medical treatment for diacetyl-morphine (heroin) addiction. JAMA 193:646-650

Donnerer J, Oka K, Brossi A, Rice KC, Spector S (1986): Presence and formation of codeine and morphine in the rat. Proc Natl Acad Sci USA 83:4560-4567

Donnerer J, Cardinale G, Coffey J, Lisek CA, Lardine I, Spector $S$ (1987): Chemical characterizations and regulation of endogenous morphine and codeine in the rat. J Pharmacol Exp Ther 242:583-587

Dougherty PM, Drath DB, Dafny N (1987): Evidence of an immune system to brain communication axis that affects central opioid function: Muramyl peptides attenuates opiate withdrawal. Eur J Pharmacol 141:253-260

Ernstrom U, Soder O (1975): Influence of adrenaline on the dissemination of antibody producing cells from the spleen. Clin Exp Immunol 21:131-140

Felton DL, Felton SY, Carlson SL, Olshowska JA, Liviat S (1985): Noradrenergic and peptidergic innervation of lymphoid tissue. J Immunol 135:755-765 
Goldstein A, Barrett RW, James IF, Lowey LI, Weitz CJ, Kimpmeyer LL, Rapoport H (1985): Morphine and other opiates from beef brain and adrenals. Proc Natl Acad Sci USA 82:5203-5207

Herman BH, O'Brien CP (1997): Clinical medications development for opiate addiction: focus on nonopioids and opioid antagonists for the amelioration of opiate withdrawal symptoms and relapse prevention. Sem Neurosci 9:158-172

Janssen PA (1976): The levamisole story. In Tucker E (ed), Progress in Drug Research. New York, Springer, pp 1-66

Marx JL (1976): Cancer immunotherapy: Focus on the drug levamisole. Science 191:57

Moertel CG, Fleming TR, Macdonald SS (1990): Levamisole and fluouracil for adjuvant therapy of resected colon carcinoma. N Engl J Med 322:352-358

Munjal ID, Schmidt D, Spector S (1996): Role of endogenous morphine in the attenuation of opiate withdrawal syndrome by $\mathrm{N}$-acetylmuramyl-L alanine-D-isoglutamine (MDP). Neuropsychopharmacology 15:99-103

O'Dorisio MS, Wood CL, O'Dorisio TM (1985): Vasoactive intestinal peptides and neuropeptides modulation of the immune response. J Immunol 135:792-796
Oka K, Kantrowitz JD, Spector S (1985): Isolation of morphine from toad skin. Proc Natl Acad Sci USA 82:18521854

Payan DG, Goetzel EJ (1985): Modulation of lymphocyte factor by sensory neuropeptides. J Immunol 135:783-786

Pfeifer AO, Samson HH (1988): Haloperidol and apomorphine effects on ethanol reinforcement in the feeding rats. Pharmacol Biochem Behav 24:343

Renoux G (1980): The general immunopharmacology of levamisole. Drugs 19:89-99

Schmidt D, Roznoski ML, Ebert MH (1990): Quantitative and qualitative HPLC analysis of monoamine neurotransmitters and metabolites in CSF and brain tissues using reductive electrochemical detection. Biochem Chromatog 4:215

Symens J, Rosenthal M (1977): Levamisole in the modulation of the immune response. The current experimental and chemical state. I. Reticuloendothelial Soc 21:175-221

Wise RA (1989): The brain and reward. In Cietman JM, Cooper SJ (eds), The Neuropharmacological Basis of Reward. Oxford, Oxford University Press, p 377 